\title{
Relationship Between Hard Total Quality Management Practices and Organizational Performance in Municipalities
}

\author{
${ }^{1}$ Abdullah ALNasser, ${ }^{1}$ Rushami Zien Yusoff and ${ }^{2}$ Rabiul Islam \\ ${ }^{1}$ School of Business Management, College of Business, \\ ${ }^{2}$ School of Economics, Finance and Banking, College of Business, \\ University Utara Malaysia, 06010 UUM, Sintok, Kedah, Malaysia
}

Received 2013-07-24, Revised 2013-08-15; Accepted 2013-08-29

\begin{abstract}
Hard total quality management has now become the major business strategy in current management and has currently been taken up by companies around the globe. The aim of the study is to determine the relationship between hard total quality management practices and performance in municipalities. A quantitative research design was adopted to collect data. Multiple regression analysis method was used to conduct this study. The findings of the study will contribute to both theory and practice. The results of this study have important contributions and implications for practitioners and policy-makers in these five developing countries. Empirical evidence revealed that hard total quality management has relationship with performance. The findings also implied that hard total quality management has positively relation with performance and there is difference in organizational performance mean between all these countries.
\end{abstract}

Keywords: Quality Management, Practice, Municipality, Performance

\section{INTRODUCTION}

The core characteristic of hard TQM is its stress on production control. Hard TQM was introduced at the onset of the industrial revolution in the earlier years of the past century. During those years, TQM was not as popular as today, although some elements of Hard TQM were being applied. In addition varying schools of TQM were also in existence such as Henry Ford, Frederick Taylor's Scientific Management which all had a significant impact to the achievement of the TQM movement (Ross, 1995). At that time, quality management involved the inspection of products to guarantee that they each achieve the specifications. The concept of hard TQM stemmed from the identification and elimination of the causes of quality issues in TQM, continuous improvement and quality awards including ISO, EFQM, Malcolm Baldrige National Quality Award and the Toyota Way. At the onset of the millennium, the focus shifted from human management to the interconnection between soft aspects of TQM and firm performance (Wilkinson et al., 1998).

The pioneering researcher who made a distinction between soft and hard TQM was (Wilkinson, 1992). On the other hand, (Rahman, 2004) stated that hard TQM are more involved in practical, numeric and systematic quality control techniques while (Al-Tarawneh, 2010) claimed that hard TQM presents the production orientation of the quality stressing on data collection, measurement, TQM tools application including Statistical Process Control (SPC), flow charts, tally charts, Pareto analysis, scatter diagrams, histograms, control charts and cause and effect analysis. Hard TQM is said to have the following three critical factors.

Total Quality Management (TQM) practices are being widely adopted by contractor companies to solve

Corresponding Author: Abdullah ALNasser, School of Business Management, College of Business, University Utara Malaysia, 06010 UUM, Sintok, Kedah, Malaysia 
problems regarding quality in the construction industry particularly to satisfy the needs of the customers. It is no surprise that TQM has now become the major business strategy in current management and has currently been taken up by companies around the globe. The construction industry is being considered as comparatively having one of the poorest quality emphases among different manufacturing and service sectors (Alotaibi et al., 2013).

\subsection{Process Management}

Process management involves all processes, process flow management, process improvement, production process, process control, process control and improvement, process design, flexible processing, advanced systems and the utilization of Just in Time (JIT) principles, use of technology and process quality (Karuppusami and Gandhinathan, 2006). On the other hand, (Mehmet et al., 2010) considers process management as the process control implementation with the help of statistical process control methods. Various statistical process control techniques are present such as control charts, cause-effect diagrams, scatter diagrams and Pareto charts.

\subsection{Quality Information and Analysis}

The suitable and timely provision of relevant data and information is of significant importance to any firm. The effective flow of communication and information among individuals and teams in an organization is not possible without a system of data and information. According to TQM gurus such as Crosby, Deming and Juran, along with the experts in the field of TQM such as (Saraph et al., 1989; Badri and Davis, 1995; Quazi and Padibjo, 1998), quality information and analysis is a significant TQM factor. Based on the study by (Chin and Sofian, 2011), easy access to relevant information facilitates the availability of knowledge in a timely manner and enables human capital's utilization of data in their work processes for the purpose of production and continuous improvement and it also enables information sharing regarding operational measures among the organization's employees which would lead to production improvement. The access to quality data and information of all stakeholders through quality tools, dependable user-friendly software and hardware systems are all important in driving and maintaining quality excellence and performance improvement (Sila, 2005).

\subsection{Strategic Planning}

Strategic planning is considered to be among the TQM critical success factors (Karuppusami and Gandhinathan, 2006). It includes mission/vision statement, quality policy, quality aims, business plan, communication methods and control and improvement of plans. It is the driver in an organization, whether profit or non-profit, in order to survive in a competitive market. For the achievement of effective strategic planning, it is imperative to take into consideration the following aspects of the organization; quality goals, effective measurement, clear unambiguous plans and accurate goals and objectives and resources. Strategic planning lays down the direction, assists in evaluating and creating synergies, facilitates prioritization and offers the basis for effective planning, motivation and control (David, 1997). Several researchers consider strategic planning as one of TQM's critical success factors (Drew and Healy, 2006; Prajogo and McDermott, 2005; Sila, 2005).

\section{MATERIALS AND METHODS}

\subsection{Theoretical Framework of the Study}

Following the thorough literature review and the identification of subsequent theoretical gaps, the research framework of the study is designed. The study model is depicted in Fig. 1 where four latent variables are presented namely Soft Total Quality Management, Hard Total Quality Management, National Culture and Organizational Performance. Soft TQM is explained by a total of five variables which are management commitment, supplier relationship, employee relations, strategic planning, education and training customer focus. On the other hand, Hard TQM is explained by process management, quality information and analysis and strategy planning. Organizational performance is explained by four variables namely financial element, customer, internal process and employee.

As stated earlier, prior studies dedicated to shedding a light on the relationship between TQM strategy and performance has been inconclusive. As a result, there is a call for current researchers to examine the variables that may improve the TQM implementation success. The framework below is used to test the postulated hypotheses.

The present chapter sheds a light on the study's research design. The chapter includes the detailed measures used by the study. Following the introduction to the chapter, the research design, questionnaire design and summaries of data analysis are explained. 


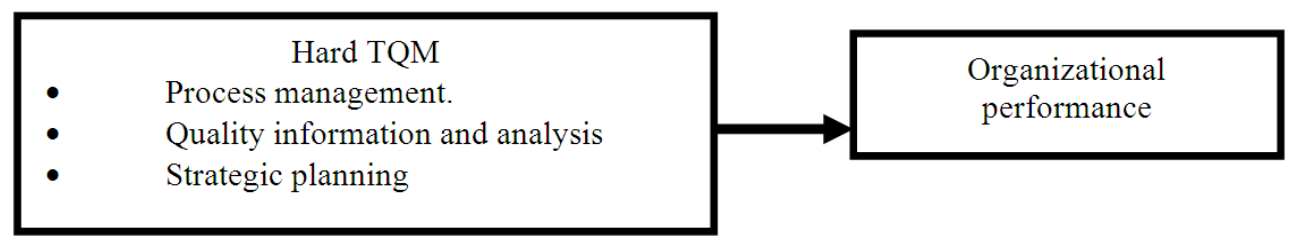

Fig. 1. Theoretical framework

\subsection{Hard Total Quality Management as Independent Variables}

Inconsistencies of the methods of measuring the construct of TQM strategy have been revealed in prior literature. In the present study, the constructs are measured by a six point Likert scale (1) "strongly disagree" to (6) "strongly agree". An average score is calculated for every construct on the basis of the items. The Hard TQM comprises of three items with 24questions. Respondents are requested to indicate their degree of agreement with each statement through a 6 point Likert scale 1 indicate strongly disagree 6 strongly agree, (Hair et al., 2011). Three critical factors of Hard TQM were derived from literature namely, process management, quality information and analysis and strategic planning.

\subsection{Pilot of the Study}

The first draft of the questionnaire has gone through many phases of revisions to rectify the problems and clear the ambiguity arose. Following that, it was a crucial step to conduct the pilot test using the data collected from a sub-set of the participants to test for the validity and reliability of the measure (Sproull, 2002). While pretest evaluation of the questionnaire involved two academicians and professionals, the pilot test involved respondent from the same pool of respondents of the study from which the real data were collected (Bradburn, 2002). However, the pilot test was conducted to refine the measure before being distributed to collect the real data of the study, to rephrase the ambiguous questions, to decide the time required responding to the questionnaire and finally to measure the reliability and validity of the measure used. Following are the steps performed to conduct the pilot test and the source of the data collected.

\subsection{Independent and Dependent Variables Relationships}

Section 2.4 hypothesis testing is done using regression model. The first part of the hypothesis test will be concern with the direct relationships between all the independent variables and the dependent variable which is the organizational performance. The first model will test the relationship between all the independent variable along the moderators as independent variable to test initially whether these variables are moderator. Baron and Kenny (1986) suggested that to test whether a variable should be included as a moderator it must be included in the equation as an independent variable and test its direct effect on the dependent variable. If the variable is found to be significant as an independent variable then transformation is need to test it indirect effect. Therefore the first model will test the direct relationship between hard TQM practices and the organizational performance Equation 1:

$$
\begin{aligned}
& \mathrm{OP}=\mathrm{a}_{\mathrm{i}}+\mathrm{b}_{1} \mathrm{TM}+\mathrm{b}_{2} \mathrm{ER}+\mathrm{b}_{3} \mathrm{E} \text { and } \mathrm{T} \\
& +\mathrm{b}_{4} \mathrm{SR}+\mathrm{b}_{5} \mathrm{PM}+\mathrm{b}_{6} \mathrm{QI}+\mathrm{b}_{7} \mathrm{SP}+\varepsilon
\end{aligned}
$$

Where:

$\mathrm{TM}=$ Top Management

$\mathrm{ER}=$ Employee Relations, $\mathrm{E}$

$\mathrm{T}=$ Education and Training

$\mathrm{SR}=$ Supplier Relationships

$\mathrm{PM}=$ Process Management

$\mathrm{QI}=$ Quality Information and Analysis

$\mathrm{SP}=$ Strategic Planning

\section{RESULTS}

\subsection{Descriptive Analysis}

Descriptive analysis describes conditions, populations and phenomena as they are the purpose of descriptive statistics are to summarize or describe a set of quantitative data. Researchers use these statistics to describe or characterize the population or sample being studied. Basically, descriptive statistics refers to means, ranges and numbers of valid cases of one variable. Table 1 shows the descriptive statistics of all principal constructs for all items. 
Table 1. Descriptive statistics of all principal constructs

\begin{tabular}{llllll}
\hline Variable & Construct & Mean & Std deviation & Skewness & Kurtosis \\
\hline Hard TQM practices & $\begin{array}{l}\text { Process management } \\
\text { Quality information } \\
\text { and analysis }\end{array}$ & 4.06 & 1.030 & -0.381 & -0.148 \\
& $\begin{array}{l}\text { Strategic planning } \\
\text { Organizational }\end{array}$ & 4.06 & 1.060 & -0.484 & -0.201 \\
$\begin{array}{l}\text { Organizational } \\
\text { Performance }\end{array}$ & \begin{tabular}{l} 
Performance \\
\hline
\end{tabular} & 4.11 & 1.090 .0520 & -0.820 & 0.536 \\
\hline
\end{tabular}

In this study, the mean for Hard TQM practices was in the range of 4.05 to 4.06 and standard deviation was in the range of 1.03 to 1.06 and the mean of the performance measure is 4.11 while its standard deviation was 0.96 . The mean scores for all variables were moderately high. There were no low level mean scores. The moderate high mean scores imply that respondents agree that all variables influence the organizational effectiveness of an organization. Among the independent variables, employee relations have the highest mean compared to other variables while the lowest was for the education and training. However, the mean score for the moderator variable culture shows that the highest mean is for uncertainty avoidance while the lowest was for Masculinity. Even though the rest of the TQM practices were not as high as employee relation their mean scores of around 4.00 imply that these activities cannot be taken lightly.

The standard deviations for all variables seem to fall between 0.88 and 1.11 , which simply reflects the existence of considerable acceptable variability within the data set. The variation value indicates that all answers on the study variables were substantially different from one respondent to another, thus, signifying the existence of tolerable variances in responses. Finally, the Skewness and kurtosis of the 13 constructs are well behaved in term of normality. The values of Skewness and kurtosis are between the ranges of -1 and +1 which indicate that there are no outlier or extreme values that might jeopardise the validity of the analysis. Consequently, all the thirteen constructs representing the four variables are ready for subsequent analysis.

\subsection{Reliability}

The reliability test was conducted to observe the internal consistency of the constructs. The alpha value is important to determine the consistency of items in each of the constructs. If the alpha value falls below the minimum value that can be considered as an adequate reliability, that factor will be dropped for the confirmatory factor analysis using structural equation modelling.

Cronbach's coefficient alpha values vary between 0 and 1 . However, there is no general agreement as to what constitutes good or very good levels of Cronbach's alpha. Gable and Wolf (1993) suggests that alpha coefficients in the high 0.80 or above should be considered good and (Cortina, 1993) suggests that alpha coefficients 0.85 or above are quite good. But, it is also important to know that (Nunnally and Bernstein, 1994) suggest that alpha values above 0.7 can be considered as adequate.

The summary of results of the internal consistency reliability test for all the constructs used in this study is presented in Table 2. Basically, constructs with Cronbach's coefficient alphas of above 0.7 will be retained.

According to (Talib et al., 2013), the top management commitment has good internal consistency with a Cronbach's alpha coefficient reported of 0.0.932. In this study the Cronbach's alpha coefficient is 0.938 . The Cronbach's alpha of Supplier relationship for this study is 0.919 , which is in line with the findings of (Talib et al., 2013) of 0.910. For employee relations the Cronbach's alpha reported above is 0.952 is higher than what was found by Yunus et al. (2013) which was 0.842 . Similarly, the construct education and training reliability $(0.925)$ is higher than what was found by (Talib et al., 2013) which was 0.902 . Other constructs followed the same trend where this study reliability for all constructs seems to be either equal or exceeds some of the studies in TQM practices. On the other hand, National culture construct seems to show acceptable level of reliability whereby all the construct display Cronbach's alpha exceeding 0.7 as recommended by Nunnally and Bernstein (1994).

\subsection{Factor Analysis}

Factor analysis is an interdependence technique and it is essential in several stages of development and assessment of measures. The underlying principle of factor analysis is the data parsimony and data interpretations in which items are condensed into common interrelated and meaningful dimensions (Churchill and Iacobucci, 2002). The primary purpose of factor analysis is to define the underlying structure among the variables in the analysis (Hair et al., 2006). 
Table 2. Cronbach's Coefficient Alpha for the Study Constructs

\begin{tabular}{llcl}
\hline Variable & Construct & Items & Cronbach's Alpha \\
\hline Organizational performance & Organizational performance & 12 & 0.933 \\
Hard TQM practices & Process management & 4 & 0.856 \\
& Quality information and analysis & 11 & 0.960 \\
& Strategic planning & 9 & 0.945 \\
\hline
\end{tabular}

The total number of items to measure all the variables for the current study is 96 . For the soft TQM practice the constructs are top management ( 8 items), Supplier relationship ( 8 items), employee relations (15 items), education and training ( 7 items) and Customer focus (6 items). Hard TQM practice consists of three constructs which are process management (4 items), quality information and analysis (11 items) and strategic planning (9 items). The moderator which is the national culture consists of 4 constructs power distance (4 items), uncertainty avoidance (4 items), Individualism (4 items) and Masculinity (4 items). The dependent variable which is organizational performance consists of total of 12 items.

In addition, only items with loadings higher than 0.50 on one factor and low cross-loadings were retained for further analysis (Nunnally, 1978). Factor loading is useful to ascertain the convergent and discriminant validity of the scales (Hurley and Hult, 1998). It also specifies the strength of the relationship between items and latent construct. According to (Hair et al., 2006), factor loadings of \pm 0.5 or greater are considered practically significant. Generally, in this study, the items were not retained if they: (i) did not load into any factor with a value of 0.5 or greater, (ii) freestanding items (i.e.,) in one factor there is only one item with high factor loading) and (iii) had cross loading on two factors. The results will be presented as follows. First the KMO results, second the scree plot, third the variance explained and lastly the rotated matrix with the factor loadings. In terms of deciding how many factors to include two criteria will be used namely, scree plot and Eigen value more than 1. Using only one of these two might lead to inclusion of unnecessary factors.

The factor analysis was run on three main variables. First, the independent variables which consist of Soft and Hard TQM practices which are formed using 5 and 3 constructs respectively. Second, the moderating variable, the national culture which consists of 4 constructs. Lastly the dependent variable which consists of one construct only. The analysis was done separately for these three variables. Table 3 shows the number of factors extracted, the KMO, the Bartlett's test of Sphericity and the variance extracted.

Since the original variable consist of 5 construct that cannot be ignored when looking at the scree plot. Therefore based on the Eigenvalues and the theoretical knowledge of the 5 constructs 4 factors were used after filtering. Similarly, Fig. 2 and 3 shows the scree plot for hard TQM practices and municipalities performance respectively. The graph also indicates that only one factor should be used because the line breaks at factor 2 and somehow flattens out. Again based on the theoretical model the hard TQM practices has three main constructs and the Eigenvalue show that 3 factor are appropriate.

Table 4 reports the factor analysis results for hard TQM practice and the factors reliability. All hard TQM practices construct are included and will be used. However, few items were deleted as shown earlier in Table 4 Out of the 11 items of quality information and analysis 6 items remains to be used for hypothesis testing. Process management maintained all its 4 items while strategic planning has only 3 items out of 9 to be used in further analysis. The reliability of these factors was tested and the results indicate that quality information and analysis has the highest mean of 0.93 followed by process management with Cronbach's alpha of 0.86 and finally strategic planning with lowest reliability of 0.84 as shown in Table 4 .

Table 5 reports the factor analysis results for the dependent variable the municipalities performance and its reliability. It is clear that the municipalities' performance reliability which is at 0.933 is still the same as before since no item was dropped after the factor analysis. Therefore these variables are ready for the next stage of analysis which is the regression analysis to test the study hypothesis. 
Abdullah ALNasser et al. / American Journal of Applied Sciences 10 (10): 1214-1223, 2013

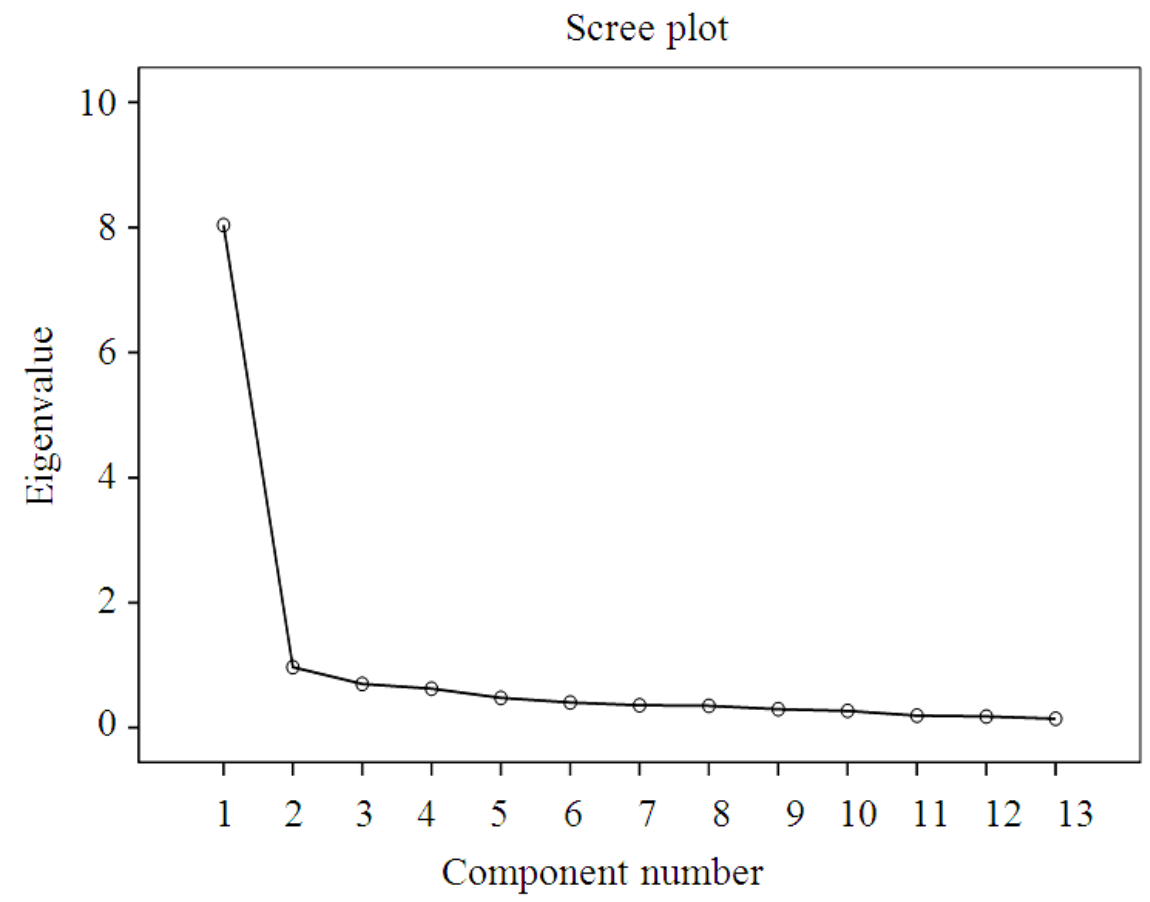

Fig. 2. Scree Plot of hard TQM practices

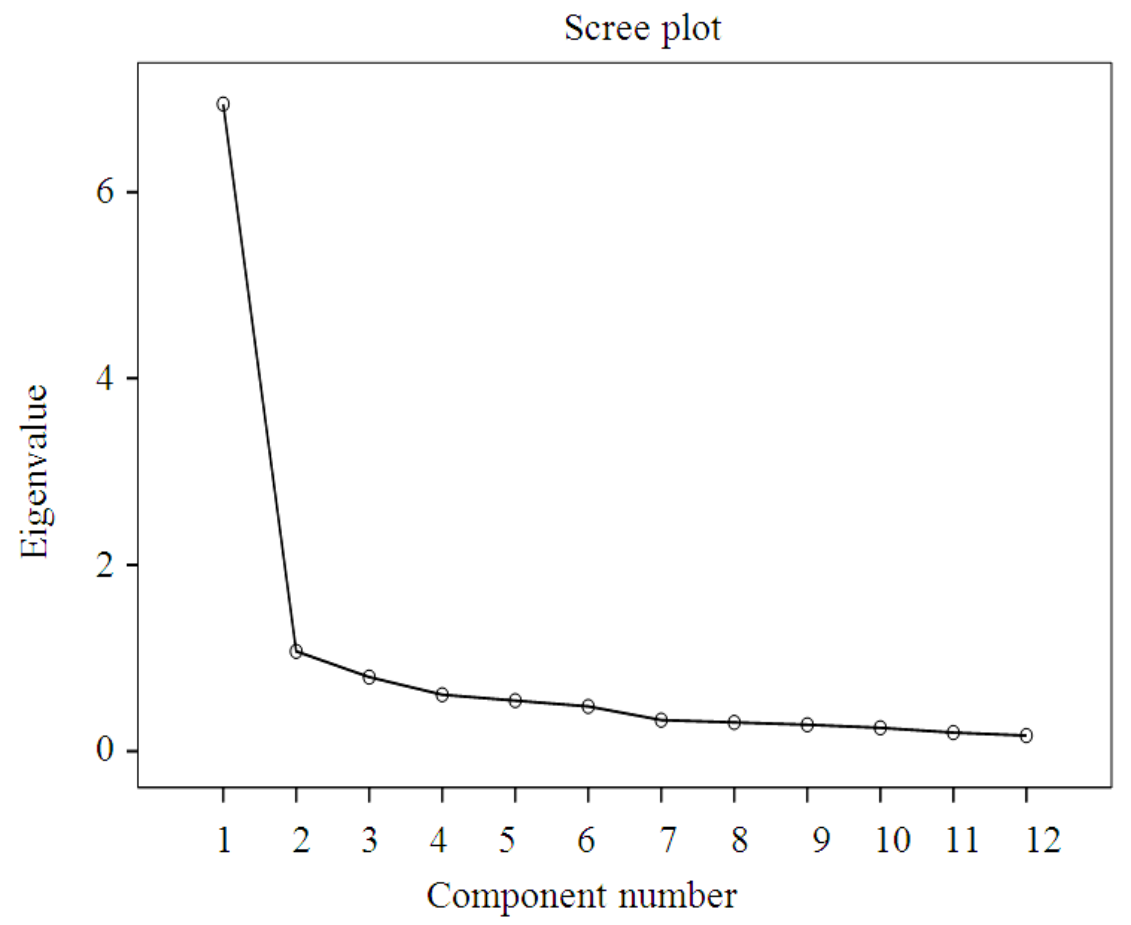

Fig. 3. Scree Plot of organizational performance 
Table 3. Exploratory factor analysis process for study variables

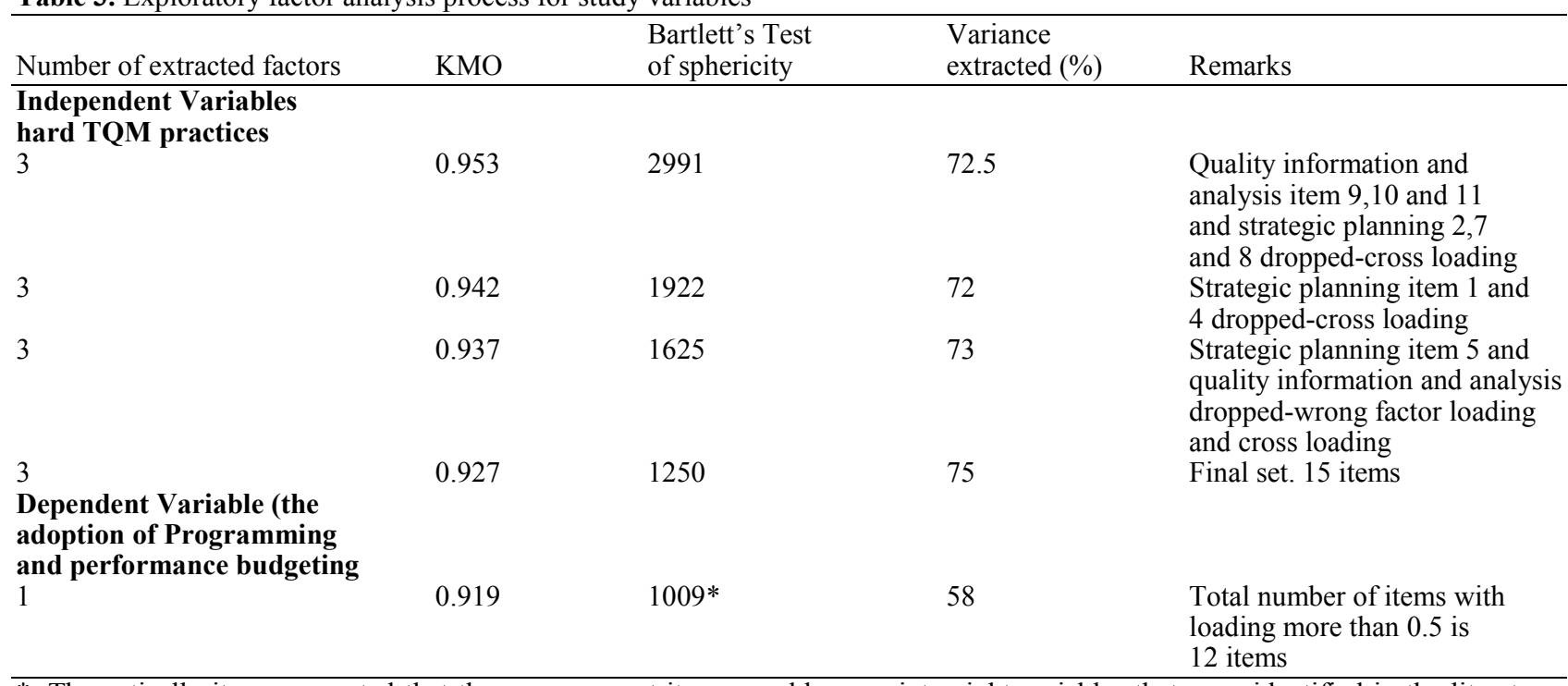

*; Theoretically it was expected that the measurement items would group into eight variables that were identified in the literature. Due to cross-loadings, the number for the independent variables (factors) decreased to 6 during the stages of the EFA process. The number drops to 6 in the final stage of the EFA process

Table 4. Factor loading and reliability test for Hard TQM practices

\begin{tabular}{|c|c|c|c|c|}
\hline $\begin{array}{l}\text { Factors } \\
\text { Item }\end{array}$ & Quality information and analysis & Process management & Strategic planning & $\begin{array}{l}\text { Reliability } \\
\text { Cronbach's Alpha }\end{array}$ \\
\hline QUAL_3 & 0.653 & & & 0.93 \\
\hline QUAL ${ }^{-} 4$ & 0.678 & & & \\
\hline QUAL_5 & 0.755 & & & \\
\hline QUAL_6 & 0.860 & & & \\
\hline QUAL_7 & 0.763 & & & \\
\hline QUAL_8 & 0.701 & & & \\
\hline PROC_1 & & 0.723 & & 0.86 \\
\hline $\mathrm{PROC}_{2}^{-} 2$ & & 0.704 & & \\
\hline $\mathrm{PROC}_{-}^{-} 3$ & & 0.790 & & \\
\hline PROC_4 & & 0.676 & & \\
\hline PLAN_3 & & & 0.701 & 0.843 \\
\hline PLAN_6 & & & 0.816 & \\
\hline PLAN_9 & & & 0.639 & \\
\hline
\end{tabular}

Table 5. Factor loading and reliability test for organizational performance

\begin{tabular}{lll}
$\begin{array}{l}\text { Component } \\
\text { Item }\end{array}$ & $\begin{array}{l}\text { Organizational } \\
\text { performance }\end{array}$ & $\begin{array}{l}\text { Reliability } \\
\text { Cronbach's Alpha }\end{array}$ \\
\hline OP_1 & 0.637 & 0.933 \\
OP_2 & 0.759 & \\
OP_3 & 0.762 & \\
OP_4 & 0.793 & \\
OP_5 & 0.710 & \\
OP_6 & 0.772 & \\
OP_7 & 0.821 & \\
OP_8 & 0.769 & \\
OP_9 & 0.763 & \\
OP_10 & 0.763 & \\
OP_11 & 0.769 & \\
OP_12 & 0.795 & \\
\hline
\end{tabular}

\section{DISCUSSION}

\subsection{Regression Analysis}

Section 3.4 will concentrate on the regression analysis of the proposed framework and to test the hypothesis derived from it. However before delving into the regression analysis there is some critical issue that needs to be addressed.

Table 6 report the regression results of the first model. The result shows that all hard TQM practices are significant and positively related with the organizational performance. The standardized beta shows the direction as well as the strength of the partial correlation between each independent variable and organizational performance. 
Table 6. Regression result for model 1

\begin{tabular}{|c|c|c|c|c|c|}
\hline Variable & $\begin{array}{l}\text { Unstandardized } \\
\text { Coefficients }\end{array}$ & $\begin{array}{l}\text { Standardized } \\
\text { Coefficients }\end{array}$ & t-value & Tolerance & VIF \\
\hline Constant & 3.285 & & 17.753 & 0.549 & 1.820 \\
\hline $\mathrm{TM}$ & $0.850^{*}$ & $0.457 *$ & 4.620 & 0.541 & 1.847 \\
\hline ER & $0.949^{*}$ & $0.433^{*}$ & 4.348 & 0.930 & 1.075 \\
\hline $\mathrm{E} \& \mathrm{~T}$ & $0.247 * *$ & $0.162 * *$ & 2.134 & 0.699 & 1.430 \\
\hline SR & $0.472 *$ & $0.287^{*}$ & 3.279 & 0.630 & 1.587 \\
\hline PM & $0.442 *$ & $0.278^{*}$ & 3.016 & 0.638 & 1.568 \\
\hline QI & $0.543^{*}$ & $0.333^{*}$ & 3.632 & 0.881 & 1.135 \\
\hline SP & $0.220^{*}$ & $0.378^{*}$ & 4.836 & 0.549 & 1.820 \\
\hline \multicolumn{6}{|l|}{$\mathrm{R}^{2}=36 \%$} \\
\hline \multicolumn{6}{|c|}{ Adj. $\mathrm{R}^{2}=32 \%$} \\
\hline \multicolumn{6}{|c|}{ F-value $=9.56^{*}$} \\
\hline
\end{tabular}

Table 7. Organizational performance mean difference

\begin{tabular}{|c|c|c|c|c|c|c|c|}
\hline \multirow[b]{2}{*}{ Variable } & \multirow[b]{2}{*}{ F-value } & \multicolumn{6}{|c|}{ Mean difference } \\
\hline & & & Saudi Arabia & Egypt & Turkey & Jordan & Qatar \\
\hline \multirow[t]{5}{*}{ Organizational performance } & $22.4 *$ & Saudi Arabia & $\begin{array}{l}----- \\
\end{array}$ & & & & \\
\hline & & Egypt & $1.07 *$ & ------ & & & \\
\hline & & Turkey & -0.03 & $1.11 *$ & ------ & & \\
\hline & & Jordan & $1.36^{*}$ & 0.29 & $1.39 *$ & ------ & \\
\hline & & Qatar & 0.01 & $-1.1 *$ & 0.05 & -1.34 & ----- \\
\hline
\end{tabular}

* Significant at $1 \%$

From Table 7 standardized beta for the hard TQM practices indicate that top management has the strongest influence on the organizational performance followed by employee relations, supplier relationship and lastly education and training. The tolerance and VIF which test Multicollinearity indicate values higher than 0.2 and less than 10 respectively indicating that the model does not suffer from severe Multicollinearity. In term of the goodness of the model the $\mathrm{R}^{2}$ and the adjusted $\mathrm{R}^{2}$ indicate that $36 \%$ and $32 \%$ respectively of the variation in the organizational performance is explained by all the independent variables. In addition, the F-value which indicates the goodness of fit is significant at $1 \%$ pointing out that the model is good. Furthermore to check the two important classical assumption of the model namely, normality and homoscedasticity the three graphs below confirm that the model does not violate any of the classical assumptions.

\subsection{Difference in Organizational Performance}

Section 3.5 will test the hypothesis whether the mean performance across countries are similar or not. The technique that is used to test the mean difference between these countries is one way analysis of variance or one way ANOVA. The result is reported in Table 7 below. The result of testing the hypothesis indicates that there is a significance difference between all these countries in terms of mean of organizational performance. However this does not show which countries is different and by how much. It is clear that Saudi Arabia has higher and significant mean than Egypt and Jordan but not turkey and Qatar. On the other hand Egypt has significantly higher mean that turkey but significantly lower than Qatar. Lastly, turkey organizational performance is significantly higher than Jordan.

\section{CONCLUSION}

This study was set up to relate Hard TQM and organizational performance relationship as reflected in the municipalities in five developing countries (Egypt, Jordan, Qatar, Saudi Arabia and Turkey). However, Hard TQM, related to the system, tools and techniques, soft quality factors are those elements of TQM deals with long-term natures and is characterized as humanistic intangible factors that are difficult to directly been measured such as top management commitment, customer focus, teamwork, 
training and empowerment and effective communication, (Thiagarajan and Zairi, 1997).

Essentially, this study was greatly motivated by the inconclusive findings, in the recent relevant literature concerning the relationship between Hard SoftTotal Quality Management and the Organizational Performance. However, the inconclusive conclusions about these relationships (Nair, 2006) have been an important unresolved issue that needs further examination. In addition to that, there are a number of organizational variables should be taken into account in the study of this relationship, (Ehigie and McAndrew, 2005; Douglas and Judge, 2001) that did not receive attention or neglect in most previous studies. Therefore the research has been studying the impact of national culture in this relationship.

The results of this study have important contributions and implications for practitioners and policy-makers in these five developing countries. Empirical evidence revealed that Hard TQM have relationship with Performance. The findings also implied that Hard TQM have positively relation with Performance, The findings also implied that there is difference in organizational performance mean between all these countries. In other words, this study provided advantageous insights on how Hard TQM can enhance the overall organizational performance. This is an expected result in municipalities are related to the services provided to citizens and nonapplication of these TQM principles will have negatively effect on the organizational performance.

\section{REFERENCES}

Alotaibi, F., R.Z. Yusoff and R. Islam, 2013. Assessing the impact of total quality management practices and quality culture with competitiveness of saudi contractors. Am. J. Applied Sci., 10: 638-645. DOI: 10.3844/ajassp.2013.638.645

Al-Tarawneh, H.A., 2010. Total Quality management and leadership an experimental investigation of iso certified companies in Jordan. Interdisciplinary $\mathrm{J}$. Contemporary Res. Bus., 2: 382-398.

Badri, MA. and D. Davis, 1995. A study of measuring the critical factors of quality management. Int. J. Q. Reliab. Manage., 12: 36-53. DOI: 10.1108/02656719510080604

Baron, R.M. and D.A. Kenny, 1986. The moderatormediator variable distinction in social psychological research: conceptual, strategic, and statistical considerations. J. Pers. Soc. Psychol., 51: 1173-82. PMID: 3806354
Bradburn, N.M., 2002. Understanding the questionanswer process. Survey Methodol., 30: 5-15. DOI: $10.4135 / 9781446262269$

Chin, K.S. and S. Saudah, 2011. The impact of human capital and total qualty management on carporate performance. J. Contemp. Res. Bus., 3: 1091-1100.

Churchill, G.A. and D. Iacobucci, 2002. Marketing Research: Methodological Foundations. 8th Edn., Harcourt College Publishers, Mason, ISBN-10: 0030331013, pp: 1006.

Cortina, J.M., 1993. What is coefficient alpha? An examination of theory and applications. J. Applied Psychol., 78: 98-104. DOI: 10.1037/00219010.78.1.98

David, F.R., 1997. Strategic Management. 6th Edn., Prentice Hall, Upper Saddle River, N.J., ISBN-10: $013486011 \mathrm{X}$, pp: 352.

Douglas, T.J. and J.Q.W. Judge, 2001. Total quality management implementation and competitive advantage: The Role of structural control and exploration. Acad. Manage. J., 44: 158-169. DOI: $10.2307 / 3069343$

Drew, E. and C. Healy, 2006. Quality management approaches in Irish organisations. TQM Mag., 18: 358-71. DOI: 10.1108/09544780610671039

Ehigie, B.O. and E.B. McAndrew, 2005. Innovation, diffusion and adoption of Total Quality Management (TQM). Manage. Deci., 43: 925-940. DOI: $10.1108 / 00251740510603646$

Gable, R.K. and M.B. Wolf, 1993. Instrument Development in the Affective Domain: Measuring Attitudes and Values in the Business and School Setting. 1st Edn., Kluwer Academic Publishers, Boston, ISBN-10: 0792393694, pp: 275.

Hair, J., W. Black, B. Babin, R. Anderson and R. Tatham, 2006. Multivariate Data Analysis. 6th Edn., Prentice-Hall International, Upper Saddle River, NJ, ISBN-10: 0130329290, pp: 899.

Hair, J.F., M.W. Celsi, A.H. Money, P. Samouel and M.J. Page, 2011. Essentials of Business Research Methods. 1st Edn., M.E. Sharpe, Armonk, New York, ISBN-10: 0765630656, pp: 477.

Hurley, R.F. and G. T.M. Hult, 1998. Innovation, market orientation and organizational learning: An integration and empirical examination. J. Market., 62: $42-54$

Karuppusami, K. and R. Gandhinathan, 2006. Pareto analysis of critical success factors of total quality management. TQM Mag., 18: 372-385. DOI: $10.1108 / 09544780610671048$ 
Mehmet, M., H. Xiaowen and G.S. Roger, 2010. The effect of quality management on mass customization capability. Int. J. Operat. Product. Manage., 30: 900922. DOI: 10.1108/01443571011075047

Nair, A., 2006. Meta-analysis of the relationship between quality management practices and firm performance-implications for quality management theory development. J. Operat. Manage., 24: 948975. DOI: 1016/j.jom.2005.11.005

Nunnally, J.C. and I.H. Bernstein, 1994. Psychometric Theory. 3rd Edn., McGraw-Hill, New York, ISBN10: 007047849X, pp: 752.

Nunnally, J.C., 1978. Psychometric Methods. 1st Edn., McGraw, New York.

Prajogo, D.I. and C.M. McDermott, 2005. The relationship between total quality management practices and organizational culture. Int. J. Operat. Product. Manage., 25: 1101-22. DOI: 10.1108/01443570510626916

Quazi, H.A. and S.R. Padibjo, 1998. A journey toward total quality management through ISO 9000 certification-a study on small- and medium-sized enterprises in Singapore. Int. J. Q. Reliab. Manage., 15: 489-508. DOI: 10.1108/02656719810196225

Rahman, S., 2004. The future of TQM is past. Can TQM be resurrected Total Q. Manage. Bus. Excell., 15: 411-422. DOI: $10.1080 / 1478336042000183550$

Ross, J., 1995. Total Quality Management: Text, Cases and Readings. 2nd Edn., St. Lucie Press, Delray Beach, FL., ISBN-10: 1884015085, pp: 465.

Saraph, J.V., P.G. Benson and R.G. Schroeder, 1989. An instrument for measuring the critical factors of quality management. Decision Sci., 20: 810-828. DOI: $10.1111 / \mathrm{j} .1540-5915.1989 . t b 01421 . x$
Sila, I., 2005. The influence of contextual variables on TQM practices and TQM-Organizational performance relationship. Bus. Rev., 4: 204-210.

Sproull, N.D., 2002. Handbook of Research Methods: A Guide for Practitioners and Students in the Social Sciences. 1st Edn., The Scarecrow Press, Lanham, ISBN-10: 0810844869, pp: 430.

Talib, F., Z. Rahman and M. Qureshi, 2013. An empirical investigation of relationship between total quality management practices and quality performance in Indian service companies. Int. J. Q. Reliab. Manage., 30: 280-318. DOI: $10.1108 / 02656711311299845$

Thiagarajan, T. and M. Zairi, 1997. A review of total quality management in practice: Understanding the fundamentals through examples of best practice application-Part I. TQM Mag., 9: 270-286. DOI: 10.1108/09544789710181899

Wilkinson, A., 1992. The other side of quality: 'Soft' issue and the human resource dimension. Total Q. Manage., 3: 323-329. DOI: 10.1080/09544129200000038

Wilkinson, A., T. Redman, E. Snap and M. Marchington, 1998. Managing with Total Quality Management. 1st Edn., Macmillan Distribution Limited, London, ISBN-10: 0333620070, pp: 216.

Yunus, M.M., N. Nordin, H. Salehi, M.A. Embil and Z. Salehi, 2013. The Use of Information and Communication Technology (ICT) in Teaching ESL Writing Skills. Canadian Center of Science and Education. 